\title{
Utilization of Rice Husk Ash as partial replacement with Cement for production of Concrete Brick
}

\author{
Le Tuan Minh ${ }^{1, *}$, and Nguyen Xuan Thanh Tram ${ }^{1}$ \\ ${ }^{1}$ Department of Silicate Materials, Faculty of Materials Technology, Ho Chi Minh city University of \\ Technology, VNU-HCM
}

\begin{abstract}
Rice husk ash (RHA) obtained from agricultural by-product could be a potential source for partial cement replacement to produce concrete brick. In this study, primary RHA and RHA heat-treated at $500^{\circ} \mathrm{C}$ were used to substitute cement in raw material mixtures. Preliminary analyses were conducted to evaluate some properties of RHA such as loss of ignition (LOI), morphology, chemical and phase compositions. X-ray Powder Diffraction (XRD) and X-Ray flourescence (XRF) results indicated that silica $\left(\mathrm{SiO}_{2}\right)$ is the major component of RHA. Transmission Electron Microscopy (TEM) images showed that RHA particles were in polygonal shapes with diameter approximately from $300 \mathrm{~nm}-1 \mu \mathrm{m}$. Cement was replaced with RHA by weight at $10 \%$ wt. The effects of RHA on the physical and mechanical properties of the aggregate cement bricks were investigated. Results demonstrated that the compressive strength of concrete bricks increased with age at curing and decreased as the percentage of RHA content increased. It is recommended that further studies should be carried out to achive optimum parameters for production of concrete brick in economic aspects.
\end{abstract}

\section{Introduction}

Currently, sustainable development is one of the most interests all over the world. Historically, sintered-clay bricks have been used as construction materials, however, the production of them created energy and environmental concerns. There is an economical benefit in using concrete bricks over sintered-clay bricks. Concrete bricks comprise of cement, fine and coarse aggregates. They are bound together tightly into a compact whole without sintering since cement has ability to be cohesive and adhesive when mixed with water. For that reason, energy and environmental issues could reduce significantly in mass production. Cement is the most expensive component among the raw materials of concrete bricks. Alternative materials have been considered in order to reduce the manufacturing cost [1-3]. Every year million tons of paddies are produced in Vietnam. This results in large amount of agricultural waste materials that are not adequately managed and utilized. Rice husk, generally considered as agricultural by-products, is mainly used for fertilizer and energy production. Rice husk ash (RHA) is obtained from the burning of rice husk. Previous

\footnotetext{
*Corresponding author: letuanminhsx@gmail.com
} 
studies showed that the predominant component of RHA is silica $\left(\mathrm{SiO}_{2}\right)$. It could chemically react with calcium hydroxide $\left(\mathrm{Ca}(\mathrm{OH})_{2}\right)$ at room temperature to achieve adhering properties and combine materials firmly. Therefore, reactive silica is also known as pozzolanic additive commonly used in cement production and the manufacture of concrete [4-6]. Despite research on RHA utilization in construction materials is not new, the use of RHA as a partial replacement to cement will solve the enviromental problem of argicultural by - product as well as contribute to reduce the manufacturing cost of concrete bricks. Therefore in this study, primary RHA and RHA heat-treated at $500^{\circ} \mathrm{C}$ were used to substitute cement in raw material mixture. The effects of RHA on the physical and mechanical properties of the aggregate cement bricks were investigated. It is expected that the cheaper concrete bricks are produced, the lower cost of civil construction could be achieved.

\section{Materials and methods}

Primary RHA was collected from Sepzone - Linh Trung 1 (Freetrend Industrial Limited). RHA was sieved using $125-\mu \mathrm{m}$ sieve to remove impurities. Then RHA was dried in an oven at $100^{\circ} \mathrm{C}$ for $24 \mathrm{~h}$. The loss of ignition (LOI) test was done by placing crucible with $1 \mathrm{~g}$ of dried RHA in furnace and igniting at $900{ }^{\circ} \mathrm{C}$ for $30 \mathrm{~min}$ to achieve a constant mass. The loss of ignition is calculated as mass percentage based on the formula (eq. 1):

$$
L O I=\frac{M_{0}-M_{1}}{M_{0}} \times 100 \%
$$

Where: $M_{o}$ is the mass of the starting sample and $M_{l}$ is the mass of the sample after ignition.

The chemical composition of RHA was determined by X-ray fluorescence spectrometry (XRF, ARL ADVANT'X, Thermo Fisher, USA). The phase composition of RHA was analyzed by X-ray diffraction (XRD) using diffractometer system (D2 Phaser, Bruker AXS $\mathrm{GmbH}$, Karlsruhe, Germany). Particle size and shape of RHA were evaluated using Transmission Electron Microscope (TEM, JEM-1400, JEOL, Japan).

The raw materials of concrete bricks were mixed according to the ratios shown in table 1 [7]. Three mixtures differing in the RHA contents were prepared. Control was the batch using cement with $0 \%$ wt of RHA. Primary RHA and RHA $-500^{\circ} \mathrm{C}$ were the batches using cement with $10 \%$ wt of primary RHA and RHA heat-treated at $500^{\circ} \mathrm{C}$, respectively. Mixing mixtures were conducted using concrete mixers for 7 -10 minutes. Then mixtures were poured into mold $(4 \times 8 \times 16 \mathrm{~cm})$. Simultaneously vibration was applied to increase homogeneity of mixture and density of finished product. After 7 and 14 days of curing with $100 \%$ humidity, concrete bricks were characterized in term of compressive strength and bulk density. Diameter and height of each specimen were measured. Then a load was applied to crush each specmen using compression machines 3000KN (C071, Matest, Italy) at a crosshead speed of $0.6 \mathrm{KN} / \mathrm{s}$.

Table 1. Mixtures of raw materials

\begin{tabular}{|c|c|c|c|c|c|}
\hline Batch/Materials & Cement (g) & Coarse Agg. (g) & Fine Agg. (g) & $\begin{array}{c}\text { RHA } \\
(\mathrm{g})\end{array}$ & Water (ml) \\
\hline Control & 300 & 2450 & 1350 & 0 & 300 \\
\hline RHA Primary & 270 & 2450 & 1350 & 30 & 300 \\
\hline RHA 500 & 270 & 2450 & 1350 & 30 & 300 \\
\hline
\end{tabular}




\section{Results and discussion}

Loss of ignition (LOI) of rice husk ash (RHA) is frequently due to the presence of moisture, unburned residues and unstable mineral phases at high temperature. In this study, LOI of primary RHA and RHA heat-treated at $500^{\circ} \mathrm{C}$ were $5.27 \% \mathrm{wt}$ and $4.13 \% \mathrm{wt}$, respectively (Table 2). Difference of LOI values could be atributed to the different amount of unburned residues and moitures [8].

Table 2. Loss of Ignition (LOI) of primary RHA and RHA heat-treated at $500^{\circ} \mathrm{C}$

\begin{tabular}{|c|c|}
\hline Sample & LOI (\%) \\
\hline RHAprimary & $5.27 \pm 0.57$ \\
\hline RHA $500^{\circ} \mathrm{C}$ & $4.13 \pm 0.55$ \\
\hline
\end{tabular}

Table 3 showed the chemical composition of primary RHA and RHA heat-treated at $500^{\circ} \mathrm{C}$. Basically, silica $\left(\mathrm{SiO}_{2}\right)$ is the major component of RHA $(90 \% \mathrm{wt})$. Besides, chemical component of RHA also included $\mathrm{K}_{2} \mathrm{O}$ and $\mathrm{CaO}$ (4\%wt) as well as some minor content of $\mathrm{MgO}, \mathrm{MnO}$ and $\mathrm{Al}_{2} \mathrm{O}_{3}$ (less than $1 \% \mathrm{wt}$ ).

Table 3. Major chemical composition of raw materials (wt $\%$ )

\begin{tabular}{|c|c|c|c|c|c|c|c|c|}
\hline Composition & $\mathrm{SiO}_{2}$ & $\mathrm{~K}_{2} \mathrm{O}$ & $\mathrm{CaO}$ & $\mathrm{MgO}$ & $\mathrm{MnO}$ & $\mathrm{P}_{2} \mathrm{O}_{5}$ & $\mathrm{Al}_{2} \mathrm{O}_{3}$ & $\mathrm{Fe}_{2} \mathrm{O}_{3}$ \\
\hline RHAprimary & 90.30 & 4.17 & 1.30 & 0.50 & 0.47 & 0.37 & 0.17 & 0.15 \\
\hline RHA $500^{\circ} \mathrm{C}$ & 87.70 & 4.04 & 1.16 & 0.52 & 0.48 & 0.40 & - & 0.17 \\
\hline
\end{tabular}

Figure 1 showed XRD patterns of primary RHA and RHA heat-treated at $500^{\circ} \mathrm{C}$. The results indicated that cristobalite that is one of $\mathrm{SiO}_{2}$ polymorphs is the main crystal phases of RHA. Quartz was also detected as minor phase. The broad peak between 21-37 implied the presence of amorphous phase of carbon and silica (as shown in Fig 1).

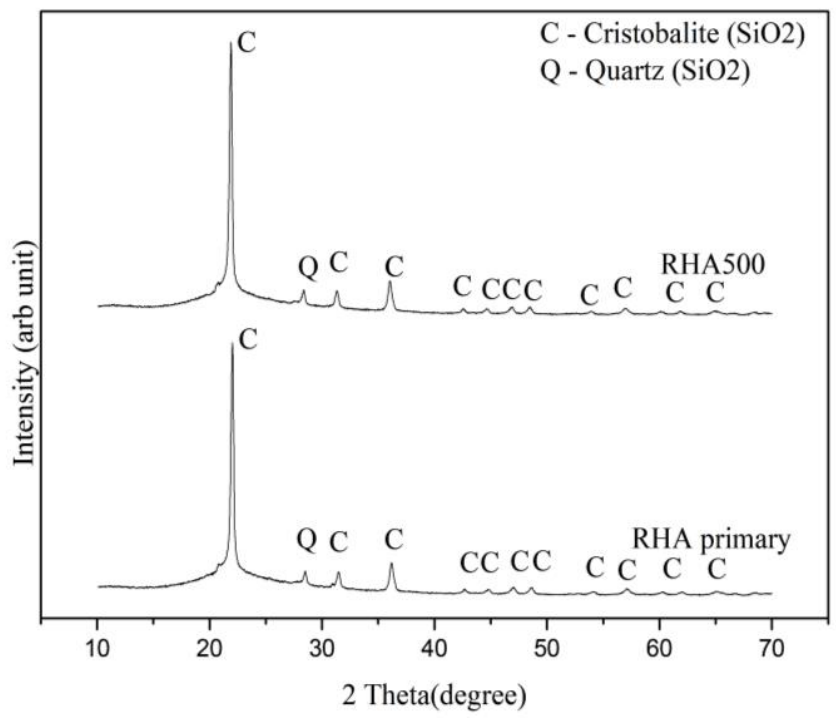

Fig. 1. XRD patterns of primary RHA and RHA heat-treated at $500^{\circ} \mathrm{C}$. 
Crystal size is calculated by using the Scherrer's equation as follows (eq. 2): [10]

$$
D=\frac{K \lambda}{B \cos \theta}
$$

With $\mathrm{B}, \mathrm{K}, \lambda$ and $\mathrm{D}$, respectively half peak width (FWHM) in radians, Scherrer constant $(\mathrm{K}=0.9)$, $\mathrm{x}$-rays wavelength $(1.5406 \AA)$ and the crystal diameter $(\mathrm{nm})$. Crystal size values of primary RHA and RHA heat-treated at $500^{\circ} \mathrm{C}$ were shown in Table 4.

Table 4. Crystal size of rice husk ash

\begin{tabular}{|c|c|c|c|}
\hline \multirow{4}{*}{ RHA primary } & 2 Theta $(\mathrm{deg})$ & FWHM $(\mathrm{deg})$ & $\mathrm{D}(\mathrm{nm})$ \\
\cline { 2 - 4 } & 22.0564 & 0.2165 & \\
\cline { 2 - 4 } & 31.4861 & 0.2362 & $342.2199 \pm 102.3046$ \\
\cline { 2 - 4 } & 36.1971 & 0.2755 & \\
\hline \multirow{3}{*}{ RHA 500 } & 21.9239 & 0.2165 & \\
\cline { 2 - 4 } & 31.3095 & 0.1378 & $607.1219 \pm 284.8269$ \\
\cline { 2 - 4 } & 35.9967 & 0.0984 & \\
\hline
\end{tabular}

TEM images showed that RHA particles were in polygonal shapes with diameter is approximately from $300 \mathrm{~nm}-1 \mu \mathrm{m}$ (as shown in figure 2). Particle size of RHA heat-treated at $500^{\circ} \mathrm{C}$ was larger than that of primary RHA. This could be explained due to the coagulation of RHA particles and development of crystal size (as shown in table 3 ) as being treated at high temperature.
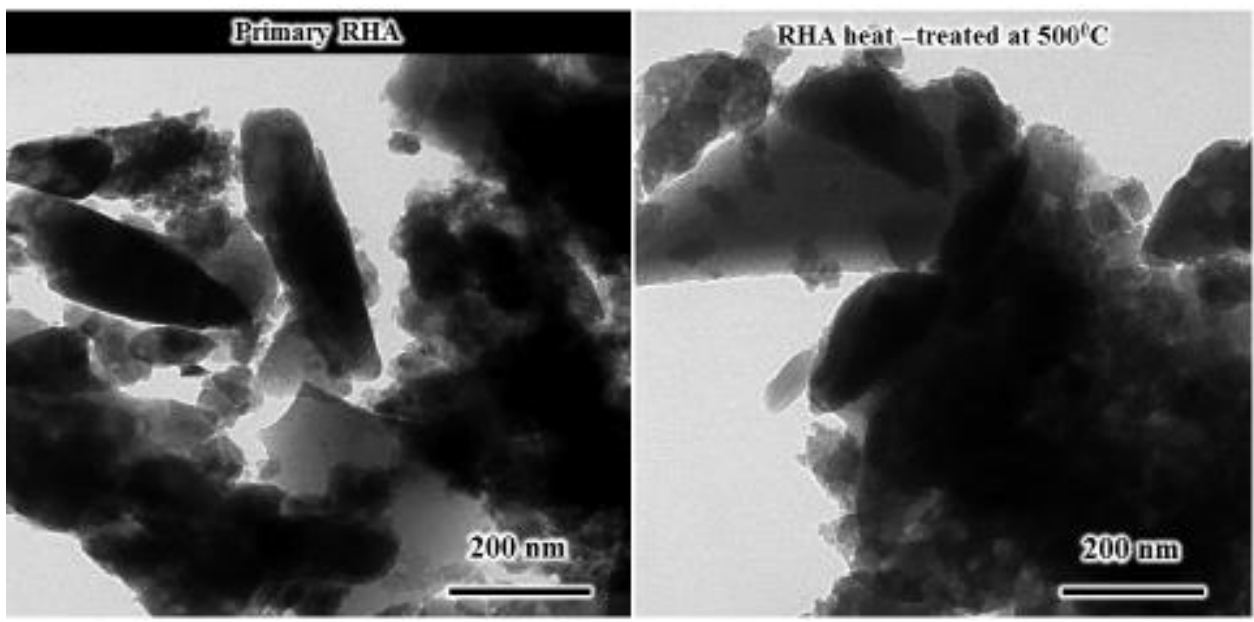

Fig. 2. TEM images of primary RHA and RHA heat-treated at $500^{\circ} \mathrm{C}$

The standard consistency of hydraulic cement was determined using Vicat Apparatus. The basic aim is to find out the water content required to produce a cement paste of standard consistency as specified by ASTM C 187 [10]. Results were showed in Table 5. The replacement of RHA changed the normal consistency of cement. The required water for normal consistency was increased as $10 \%$ replacement of RHA by weight of cement. Comparison between primary RHA and RHA500, higher quantity of water needed as using RHA heat-treated at $500^{\circ} \mathrm{C}$. 
Table 5. The normal consistency of hydraulic cement.

\begin{tabular}{|l|c|c|}
\hline Sample & Water $(\mathrm{ml})$ & Slump of Vicat $(\mathrm{mm})$ \\
\hline Cement $(400 \mathrm{~g})$ & 130 & $6 \pm 0.5$ \\
\hline Cement $(360 \mathrm{~g})+$ RHA Primary $(40 \mathrm{~g})$ & 145 & $5 \pm 0.5$ \\
\hline Cement $(360 \mathrm{~g})+$ RHA500 $(40 \mathrm{~g})$ & 155 & $6.5 \pm 0.5$ \\
\hline
\end{tabular}

Table 6 showed compressive strength and bulk density of concrete bricks after 7 and 14 days of curing with $100 \%$ humidity. Results demonstrated that the compressive strength of concrete bricks increased with age at curing and decreased as the percentage of RHA content increased. RHA can replace cement from $10-40 \% \mathrm{wt}$, therefore, it is suggested that various RHA substitution contents could be investigated in the next studies [11].

Table 6. Compressive strength and bulk of concrete bricks after 7 and 14 days of curing with $100 \%$ humidity.

\begin{tabular}{|c|l|l|l|}
\hline Days & Sample & Bulk Density $\left(\mathrm{kg} / \mathrm{m}^{3}\right)$ & Compressive strength $(\mathrm{MPa})$ \\
\hline \multirow{3}{*}{7} & Control & $2248.46 \pm 17.81$ & $3.75 \pm 0.10$ \\
\cline { 2 - 4 } & RHA Primary & $2103.05 \pm 48.64$ & $3.60 \pm 0.11$ \\
\cline { 2 - 4 } & RHA500 & $2192.52 \pm 26.65$ & $3.65 \pm 0.05$ \\
\hline \multirow{3}{*}{14} & Control & $2175.31 \pm 75.01$ & $4.97 \pm 0.31$ \\
\cline { 2 - 4 } & RHA Primary & $2300.55 \pm 25.34$ & $3.93 \pm 0.12$ \\
\cline { 2 - 4 } & RHA500 & $2216.10 \pm 31.18$ & $3.77 \pm 0.09$ \\
\hline
\end{tabular}

Fig 4 showed the practical images of specimens before and after mechanical testing. It can be seen that pores on the surface of RHA specimen was higher than that of control specimen. After mechanical load test, control specimen was cracked in one direction whereas RHA specimen was destroyed in multi-direction.
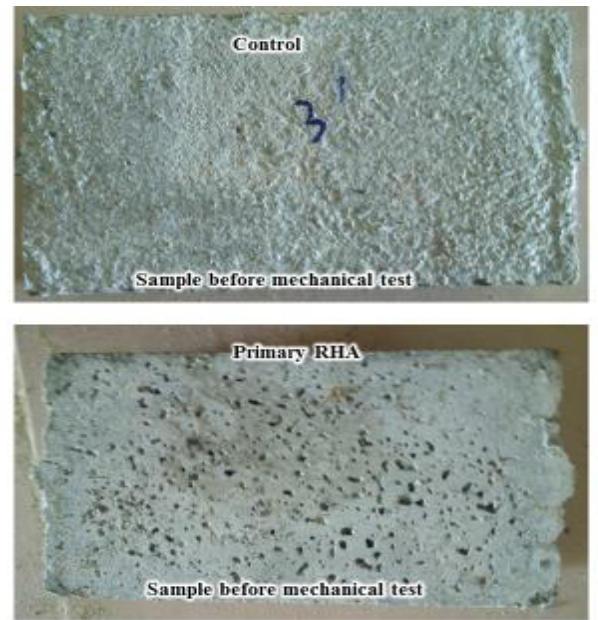
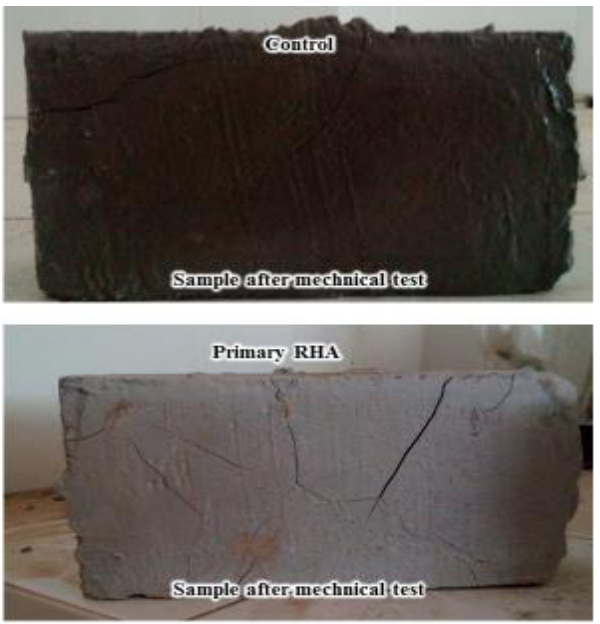

Fig. 4. Specimens before and after mechanical testing. 


\section{Conclusion}

The rice husk ash (RHA) could be used to replace cement for production of concrete bricks to eeduces material cost and emission of $\mathrm{CO}_{2}$ due to less cement utilization. However, the content of RHA needs to modify to achive optimum parameters for production of concrete brick. Rice husk ash after heat treatment is advatageous on reducing organic component that may contribute to chemical resistance of concrete brick.

The authors would like to express appreciation for the financial support of the scientific research grant of Ho Chi Minh City University of Technology for undergraduate (SVCQ -2015-CNVL-126).

\section{References}

1. G.A. Habeeb, H.B. Mahmud, Mater. Res.,13(2), 185 (2010)

2. S. Singh, D. Kumar, Int. J. Innov. Res. Adv. Eng., 1(6), 214 (2014)

3. A. Kachwala, A. Pamnani, A. Raval, Int. Res. J. Eng. Technol., 12(5), 175 (2015)

4. S.H. Sathawane, V.S. Vairagade, K.S. Kene, Procedia Eng., 51, 35 (2013)

5. A. Shukla, C.K. Singh, A.K. Sharma, Int. J. Earth Sci. Eng., 4(6), 965 (2011)

6. I.O. Obilade, Int. J. Eng., 5(4), 8269 (2014)

7. S.H. Kosmatka, B. Kerkhoff, W.C. Panarese, Design and control of concrete mixtures (Portland Cement Association, USA, 2002)

8. C. Santasnachok, W. Kurniawan, H. Hinode, J. Life Sci., 10(3) (2015)

9. E.M. Ginting, B. Wirjosentono, N. Bukit, H. Agusnar, Chem. Mater. Res., 6(7), 14 (2014)

10. ASTM C 187 - 98 , Standard Test Method for Normal Consistency of Hydraulic Cement, ASTM C 187 - 98 in: Annual Book of ASTM Standards, Vol 04.01, (1995)

11. ASTM C 109 - 88 , Standard Test Method for Compressive Strength of Hydraulic Cement Mortars, ASTM C 109 - 88 in: Annual Book of ASTM Standards, Vol 04.01, (1995) 